\title{
O DIREITO NA SOCIEDADE DA INFORMAÇÃO E PERSPECTIVAS PARA A SOCIEDADE DO CONHECIMENTO
}

\author{
THE LAW IN THE INFORMATION SOCIETY AND \\ PROSPECTS FOR THE KNOWLEDGE SOCIETY
}

\author{
MARCO ANTONIO BARBOSA ${ }^{1}$ \\ MARCO AURELIO MOURA DOS SANTOS ${ }^{2}$
}

\begin{abstract}
RESUMO: Abordam-se os conceitos de sociedade da informação e do conhecimento, no contexto de revolução tecnológica e as principais alterações provocadas na contemporaneidade pela facilitação do acesso à informação e a repercussão no campo do Direito. Identifica-se o fator econômico (o mercado) como o principal causador das mudanças estruturais e institucionais que levam os diferentes campos da vida social a ganhar autonomia e racionalidades próprias, nem sempre congruentes entre si, abrindo para o Direito enormes desafios e novas possibilidades de soluções e expressões. Verifica-se que o processo econômico global resulta em desigualdade crescente nas sociedades contemporâneas e em alterações nas identidades pessoais, coletivas e nas noções clássicas de distância, tempo e espaço. Indaga-se sobre as possibilidades e os caminhos dessas sociedades pluralistas em direção a uma sociedade do conhecimento entendida como aquela em que haveria maior equilíbrio na produção da informação e do conhecimento por meio de processos de colaboração intercultural. Conclui-se que para isso é necessário rearranjo de forças e maior equilíbrio entre produtores e consumidores de informações/conhecimentos, investimento em educação intercultural profunda, entre outras mudanças.
\end{abstract}

PALAVRAS-CHAVE: Direito; Conhecimento; Informação; Mercado; Globalização; Identidade; Tempo; Espaço; Cultura.

ABSTRACT: It addresses the concepts of information society and knowledge in the context of technological revolution and major changes in contemporary caused

Artigo recebido em 11.12.2013. Pareceres emitidos em 09.04.2014, 18.06.2014 e 04.09.2014.

Artigo aceito para publicação em 06.10.2014.

${ }^{1}$ Doutor e Mestre em Direito pela Universidade de São Paulo, Professor e Orientador do Programa de Mestrado em Direito da Sociedade da Informação no Centro Universitário das Faculdades Metropolitanas Unidas - FMU/SP - São Paulo/SP. mabarbosa@fmu.br

${ }^{2}$ Mestrando em Direito da Sociedade da Informação no Centro Universitário das Faculdades Metropolitanas Unidas - FMU/SP - São Paulo/SP, Bacharel em Direito, Especialista em Direito Público. Servidor da Justiça Federal em São Paulo. Professor do Curso de Direito no Centro Universitário das Faculdades Metropolitanas Unidas - FMU/SP - São Paulo.marco.santos@fmu.br 
by facilitating access to information and the impact in the field of law. Identifies the economic factor (the market) as the main cause of the structural and institutional changes that lead to the different fields of social life to gain autonomy and rationality own, not always congruent, opening for Law enormous challenges and new possibilities solutions and expressions. It appears that the global economic process results in growing inequality in contemporary societies and changes in personal identities, collective, and the classical notions of distance, time and space. One wonders about the possibilities and the ways these pluralistic societies towards a knowledge society understood as one in which there would be more balance in the production of information and knowledge through processes of intercultural collaboration. We conclude that this requires rearrangement of forces and greater balance between producers and consumers of information/knowledge, deep investment in intercultural education, among other changes.

KEYWORDS: Law; Knowledge; Information; Market; Globalization; Identity; Time; Space; Culture.

SUMÁRIO: Introdução; 1. Direito na Sociedade do Conhecimento; 2. O Mundo é Plano: a explosão das noções de distância, tempo e trabalho; 3. Diversidade; Ética e Educação Intercultural Profunda; 4. A Partilha do Conhecimento; Considerações Finais; Referências Bibliográficas.

CONTENTS: Introduction; 1 . Law in the Knowledge Society; 2 . The World is Flat: the explosion of the notions of distance, time and work; 3. Diversity; Profound Ethical and Intercultural Education; 4. The Sharing of Knowledge; Final Thoughts; References.

\section{INTRODUÇÃO}

Registre-se que a expressão "sociedade da informação" passou a ser utilizada, nos últimos anos, como substituta do conceito complexo de "sociedade pós-industrial" e como forma de transmitir o conteúdo específico do "novo paradigma técnico econômico". Nesse diapasão, entende-se que as transformações em direção à sociedade da informação, em estágio avançado nos países industrializados, constituem uma tendência dominante mesmo para economias menos industrializadas e definem um novo paradigma, o da tecnologia da informação, que expressa a presente transformação tecnológica em suas relações com a economia e a sociedade. Há quem diga, no entanto, a exemplo de José de Oliveira Ascensão, que a noção de sociedade da informação não é, no entanto, um conceito técnico, mas sim um "mero slogan". ${ }^{3}$

A questão econômica tem se tornado central no trato da informação e do conhecimento e considerando a opinião de muitos dos especialistas sobre o tema torna-se necessário abordar a influencia que o mercado exerce. Destaca-se o caráter desigual e injusto da sociedade da informação, assegurado pelo o abismo existente entre os chamados países desenvolvidos e em desenvolvimento, os crescentes problemas derivados das imigrações e conflitos étnicos que assumem proporções mais intensas e diversificadas, a crise nos mercados de trabalho e na valorização da mão de obra, a ausência da

\footnotetext{
${ }^{3}$ ASCENSÃO, José de Oliveira et al. Estudos sobre Direito da Internet e da Sociedade da Informação. Coimbra: Almedina, 2001. p. 87.
} 
promoção ao respeito às diversidades culturais e à proteção ao conhecimento das sociedades tradicionais.

Assim, discute-se inicialmente o Direito e o poder neste novo contexto chamado de sociedade da informação, em seguida, aborda-se a diversidade cultural e os efeitos sobre as diferentes identidades decorrentes da globalização, do mercado, das novas tecnologias e do fato de que a informação e o conhecimento transformaram-se no principal produto do capitalismo, com implicações sobre a ética, levando à discussão de sistema de educação como caminho para se atingir a sociedade do conhecimento. No terceiro item trata-se da explosão das noções de distância, tempo e trabalho e de seus efeitos sociais e jurídicos e por fim discute-se a partilha do conhecimento como caminho para sociedades mais tolerantes e solidárias e os problemas colocados no presente. Conclui-se que a informação e o conhecimento na atualidade foram transformados em mercadoria com consequências deletérias em todos os tipos de relações, com evidentes implicações jurídicas, como ao longo de todo o artigo se discute.

\section{DIREITO NA SOCIEDADE DO CONHECIMENTO}

$\mathrm{Na}$ atualidade existe o questionamento se a informação, produto principal da recente revolução tecnológica, seria capaz de produzir conhecimento. Koichiro Matsuura, diretor-geral da UNESCO, afirma que informação não é conhecimento. Para ele na atualidade verifica-se o surgimento de uma incipiente sociedade da informação, isso porque existem reais e evidentes obstáculos para uma real sociedade do conhecimento. Entre os quais devem ser considerados: o abismo digital, pois dois milhões de pessoas não são conectadas à rede elétrica e três quartos da população mundial têm pouco ou nenhum acesso às telecomunicações básicas; o abismo do conhecimento, pela concentração de conhecimento em áreas geográficas restritas; o problema do equilíbrio entre a universalidade do conhecimento e a propriedade intelectual; as divisões sociais, nacionais, urbanas, familiares, educacionais, culturais, de gênero, entre outras. ${ }^{4}$

O então diretor-geral da UNESCO acredita que o conhecimento deve possuir duas qualidades notáveis: a não rivalidade, e, uma vez prescrito o período de proteção sobre a propriedade intelectual, a não exclusividade. A partilha do conhecimento para Koichiro Matsuura seria uma dos caminhos para promover uma guerra efetiva contra a pobreza, a prevenção das grandes ameaças à saúde e para promover desenvolvimento sustentável. Incluem-se ainda na proposta da UNESCO o aproveitamento dos conhecimentos locais e tradicionais e a promoção da diversidade linguística. ${ }^{5}$

\footnotetext{
${ }^{4}$ MATSUURA, Koishiro, apud BARBOSA, Marco Antonio. Poder na Sociedade da Informação. PAESANI, Liliana Minardi. (Coordenadora) O Direito na Sociedade da Informação. São Paulo: Atlas, 2007. p. 58.

${ }^{5}$ Idem.
} 
Há posições divergentes quanto ao uso e a legitimidade para a partilha dos chamados conhecimentos tradicionais, com consequências jurídicas, econômicas, culturais e sociais. A questão central é saber se as propostas do relatório da UNESCO são compatíveis com os interesses e os direitos dos povos detentores desses conhecimentos. A ideia de não-rivalidade e da não exclusividade do conhecimento dos povos tradicionais voltada ao "bem da humanidade" esta longe de ser considerada apenas benigna. ${ }^{6}$ Há sempre interesses econômicos em questão e o conhecimento também se transformou em mais um bem de uso comercial. Aliás, para muitos, trata-se do mais importante bem da atual fase do capitalismo.

A ideia de que o conhecimento é um produto e passou a ser vendido já está presente na obra hoje clássica, intitulada $A$ condição pós-moderna, de Jean-François Lyotard. O filósofo menciona que o conhecimento se transforma em informação e deixa de ser matéria indefinível na mente e torna-se produto passível de compra e venda. Lyotard sugeriu, ainda, que a relação com o conhecimento sofreu mudança após a Segunda Guerra Mundial e o uso das tecnologias.

Parece que a incidência destas informações tecnológicas sobre o saber deve ser considerável. Ele é ou será afetado em suas duas principais funções: a pesquisa e a transmissão de conhecimentos. Quanto à primeira, um exemplo acessível ao leigo é dado pela genética, que deve seu paradigma teórico à cibernética. Há uma infinidade de outros exemplos. Quanto à segunda, hoje em dia já se sabe como, normalizando, miniaturizando e comercializando os aparelhos, modificam-se as operações de aquisição, classificação, acesso e exploração dos conhecimentos. É razoável pensar que a multiplicação de máquinas informacionais afeta e afetará a circulação dos conhecimentos, do mesmo modo que o desenvolvimento dos meios de circulação dos homens (transportes) dos sons e, em seguida, das imagens (media). ${ }^{7}$

Os computadores transformaram nossas atitudes, ao mesmo tempo em que o conhecimento e a informação puderam ser arquivados em bancos de dados, deslocados, comprados e vendidos. Isso é o que Lyotard chama de "mercantilização" do conhecimento com várias implicações: a primeira ressalta Lyotard-, é que o conhecimento que se exterioriza não é mais algo que ajuda no desenvolvimento da mente, algo capaz de nos transformar; o conhecimento também se desconecta das questões sobre a verdade - ele é julgado não em termos do quanto é verdadeiro, mas em termos do quão bem

\footnotetext{
${ }^{6}$ MATSUURA, Koishiro, apud BARBOSA, Marco Antonio. Poder na Sociedade da Informação. PAESANI, Liliana Minardi. (Coordenadora) O Direito na Sociedade da Informação. São Paulo: Atlas, 2007. p. 58.

${ }^{7}$ LYOTARD, Jean-François. A Condição Pós-moderna. Rio de Janeiro: José Olimpio Editora, 1988. p. 04.
} 
serve a certos fins. ${ }^{8}$ Quando deixamos de fazer perguntas sobre o conhecimento, tais como "isso é verdadeiro?", e começamos a questionar "como isto pode ser vendido?", o conhecimento torna-se um produto.

Pode-se então esperar uma explosiva exteriorização do saber em relação ao sujeito que sabe (sachant), em qualquer ponto que este se encontre no processo de conhecimento. $\mathrm{O}$ antigo princípio segundo o qual a aquisição do saber é indissociável da formação (Bildung) do espírito, e mesmo da pessoa, cai e cairá cada vez mais em desuso. Esta relação entre fornecedores e usuários do conhecimento e o próprio conhecimento tende e tenderá a assumir a forma que os produtores e os consumidores de mercadorias têm com estas últimas, ou seja, a forma valor. O saber é e será produzido para ser vendido, e ele é e será consumido para ser valorizado numa nova produção: nos dois casos, para ser trocado. Ele deixa de ser para si mesmo seu próprio fim; perde o seu "valor de uso".

Lyotard alertou que os Estados-nações e as corporações privadas costumam controlar o fluxo de conhecimento, decidindo quem pode acessar qual tipo de conhecimento, e quando. ${ }^{10}$

Sob a forma de mercadoria informacional indispensável ao poderio produtivo, o saber já é e será um desafio maior, talvez o mais importante, na competição mundial pelo poder. Do mesmo modo que os Estadosnações se bateram para dominar territórios, e com isto dominar o acesso e a exploração das matérias-primas e da mão-de-obra barata, é concebível que eles se batam no futuro para dominar as informações. Assim encontra-se aberto um novo campo para as estratégias industriais e comerciais e para as estratégias militares e políticas. ${ }^{11}$

A questão econômica tem se tornado central no trato da informação e do conhecimento, mas não há como deixar de mencionar o poder enquanto fundamento da questão econômica. O poder é assim mencionado por Otilia Abrantes em A cidade do Pensamento único: desmanchando consensos, utilizando uma concepção foucaultiana:

O poder, como bem diria Foucault, se esgueira pelas beiradas, busca não ser percebido para influir tanto mais, procura a obediência do outro sem que este perceba, inventa privilégio que a vítima pensa ser mérito, usa o melhor conhecimento para imbecilizar. ${ }^{12}$

\footnotetext{
${ }^{8}$ LYOTARD, Jean-François. A Condição Pós-moderna. Rio de Janeiro: José Olimpio Editora, 1988. p. 04.

${ }^{9}$ Idem. p. 05.

${ }^{10}$ BUCKINGHAM, Will e outros. Tradução de Douglas Kim. O Livro da Filosofia. São Paulo: Globo, 2011. p. 299.

${ }^{11}$ LYOTARD, Jean-François. A Condição Pós-moderna. Rio de Janeiro: José Olimpio Editora, 1988. p. 05.

12 ARANTES, Otilia; VAINER, Carlos; MARICATO, Emilia. A Cidade do Pensamento Único: desmanchando consensos. Petrópolis: Vozes, 2000. p. 11.
} 
O poder na concepção de Foucault é exercido dentro das relações humanas e não é apenas o poder exercido pelo Estado de forma generalizada. É exercido por todos os indivíduos sendo que o conhecimento e a informação constituem os denominados "saberes". ${ }^{13}$ Foucault adota o método arqueológico para fazer a sua análise dos saberes. Isso implica na recusa de que existe uma evolução do conhecimento, que este segue em direção à verdade e de que a verdade se dá em oposição ao conhecimento comum.

A riqueza do método arqueológico, concebido por Foucault, possibilita uma reflexão sobre as ciências do homem entendidas enquanto saberes. Investiga suas condições de existência por meio da análise do "que dizem, como dizem e por que dizem - neutralizando a questão de sua cientificidade". ${ }^{14}$

Pedro Demo afirma que o conhecimento é ambivalente e no processo de globalização aponta para formatos mais globalizantes de discriminação $0^{15}$. Ainda sobre o contexto atual do conhecimento e da informação na economia, acrescenta:

O pano de fundo capitalista revela que não se trata apenas da "sociedade", mas principalmente da "economia" da informação, que, ademais, facilita enormemente a volatilidade do capital, sem pátria, globalizado. Esta marca estiola as expectativas ingênuas de que a globalização traria benefícios repartidos com todos globalmente. As pretensões "universalizantes" do conhecimento, tão bem expressa na idéia de "universidade", redundaram no aprisionamento ostensivo de suas energias no mercado, assinalando que o redistributivo é, como regra, inverso. ${ }^{16}$

A atual velocidade que a informação e a comunicação atingiram no desenvolvimento tecnológico aponta para a ideia de que o mundo tornou-se uma "pequena aldeia", porém outros fatores, como os interesses econômicos buscados pelo processo de globalização, foram responsáveis pelo uso ambivalente da informação e do conhecimento como mola mestra de um processo econômico com supervalorização do consumo.

Assim, como pensar no "Direito" para a chamada sociedade do conhecimento, diante das constantes mudanças que provocam alterações nas concepções de tempo, de espaço, de nação, de conhecimento, de identidade, cultura, entre outros conceitos, quando o próprio Direito busca cristalizar comportamentos e estabelecer sanções que se protraem no tempo?

A sociedade da informação realiza muito menos do que se propõe e frequentemente transmite informação ambivalente, manipulada e manipulável,

\footnotetext{
${ }^{13}$ MACHADO, Roberto. Ciência e Saber: a trajetória da arqueologia de Michel Foucault. Rio de Janeiro: Graal, 1981. p. 09.

${ }^{14}$ Idem. p. 11.

15 DEMO, Pedro. Ambivalências da Sociedade da Informação. Ciência da Informação, Brasília, v. $29, n^{\circ} 2$, p. 37-42, maio/ago. 2000. p. 38.

${ }^{16}$ Idem.
} 
assim como, a globalização engloba muito menos pessoas e povos do que o discurso ufanista sobre ela pretende. A mercadoria vem antes, e neste mercado, a informação e o conhecimento também são produtos. ${ }^{17}$

Peter Sloterdijk afirma que se o efeito Gutenberg em seu tempo desencadeou uma forte onda de satisfação pelo acesso ao conhecimento escrito, a popularização atual das mídias eletrônicas corresponde a um élan sem precedente em direção à oferta de não importa qual conteúdo.

Não se trata de um acaso se o conceito de informação impôs-se ao mesmo tempo em que as novas mídias. É apenas na era da abstração midiática que a homogeneização do saber, no sentido de uniformização da informação, pôde conduzir-se à sua perfeição técnica - para além do nivelamento de todo conteúdo da consciência ao lugar de "representações", tal como a praticou a filosofia transcendental. Da mesma maneira que a filosofia pós-cartesiana fundava-se na ideia de que o livro impresso e o sujeito têm a mesma idade, o pensamento contemporâneo supõe que a informacão e os utilizadores eletrônicos das mídias nasceram na mesma época. $^{18}$

O filósofo alemão afirma que essas mídias tornaram praticável o que chamamos de rede mundial, compreendidos também os usuários individuais naquilo chamado de rotinas simples, mas mais ainda porque se introduz, no uso das mídias digitais, uma relação fundamentalmente nova entre os conteúdos e os utilizadores. "A melhor maneira de caracterizar essa tendência é o conceito de exteriorização, a condição de que se retire todo valor moral dessa expressão. A exteriorização significa que uma forma mais leve da subjetividade, digamos o 'Eu usuário' começa a substituir a forma mais pesada da subjetividade, o 'Eu culto', dos Tempos modernos". ${ }^{19}$

Sustenta que a virada técnica desincumbe os indivíduos das exigências ligadas à formação integral da personalidade, como ocorria ao tempo em que se falava de pessoas bem educadas. É exatamente contra ideia de pessoa culta que se dirige a onda de não responsabilização decorrente das novas mídias. Seu sentido de facilitação torna-se evidente na medida em que a subjetividade do leitor se dissolve para ir em direção a uma subjetividade de usuário.

Usuário é o agente que não tem mais necessidade de tornar-se um sujeito formado segundo regras da cultura porque ele pode se livrar do peso consistente a recolher experiências. A palavra "livrar-se" designa aqui o efeito de desincumbir que os conteúdos homogêneos, as informações,

\footnotetext{
${ }^{17}$ DEMO, Pedro. Ambivalências da Sociedade da Informação. Ciência da Informação, Brasília, v. 29, no 2, p. 37-42, maio/ago. 2000. p. 38.

18 SLOTERDIJK, Peter. Le Palais de Cristal. Traduit de l'allemand par Olivier Mannoni. France: Pluriel, 2010. Tradução pessoal, p. 313.

${ }^{19}$ Idem.
} 
asseguram aos seus usuários desde que não se tenha que adquirir por meio de uma formação consumidora do tempo, mas que se pode "buscá-la" por meio de técnicas adequadas. É fato que o usuário não para de recolher - desde então ele deve à sua maneira conferir justiça à qualidade cumulativa de eventos cognitivos que se sucedem uns aos outros. O que ele recolhe, no entanto, não são experiências, quer dizer complexos de conhecimentos integrados sob a forma pessoal, ordenados sob a forma narrativa e conceitual: são endereços onde se pode dispor de agregados de conhecimento mais ou menos colocados em forma, se por uma razão ou outro, puder querer ter recurso a eles. ${ }^{20}$

Jose Eduardo Faria em Direito e Globalização Econômica: Implicações e Perspectivas traz um importante referencial para entender a crise do direito moderno por conta do processo econômico de globalização e começa realizando as seguintes indagações:

\begin{abstract}
Alimentada por uma nova revolução tecnológica contínua, a globalização econômica tornou-se um fato. Vencida a fase inicial do desafio da integração dos mercados, vive-se agora a fase dos seus desdobramentos institucionais e jurídicos. Qual o papel dos Estados nacionais nesse novo cenário? Qual a eficácia e qual o alcance de seus instrumentos legais? O que esperar do direito positivo em sua versão normativista convencional, com suas regras hierarquizadas por meio de critérios lógico-formais, em contextos cada vez mais complexos, mutáveis e policêntricos? Se a conversão das economias nacionais num sistema mundial único está conduzindo ao redimensionamento do princípio da soberania nacional, qual o futuro das Constituições-dirigentes, aquelas que, além de consistirem num estatuto organizatório definidor de competência e regulador de processos, atuam também como uma espécie de "estatuto político" dos Estados intervencionistas, estabelecendo o que (como e quando) o legislador e os governantes devem fazer para a concretização das diretrizes programáticas constitucionais. ${ }^{21}$
\end{abstract}

O Estado na sua matriz liberal-clássica, através de uma democracia representativa podia ser vista como uma técnica que visava absorver, por meio de seus procedimentos eleitorais, legislativos, decisórios e adjudicantes, as diferentes demandas e distintos anseios de sociedades pluralistas. ${ }^{22}$ As crises enfrentadas nos anos setenta do século XX (petróleo 1973/79) que deflagraram mudanças nas políticas do fluxo de capital, recessão nos países desenvolvidos, abriram caminho para a revolução tecnológica desencadeada com o objetivo de reduzir o impacto do custo da energia e do trabalho

\footnotetext{
${ }^{20}$ SLOTERDIJK, Peter. Le Palais de Cristal. Traduit de l'allemand par Olivier Mannoni. France: Pluriel, 2010. Tradução pessoal, p. 313.

${ }^{21}$ FARIA, José Eduardo. Direito e Globalização Econômica: Implicações e Perspectivas. São Paulo: Malheiros, 1996. p. 05.

${ }^{22}$ Idem.
} 
no preço final dos bens e serviços, foram responsáveis por produzir mudanças nas engrenagens decisórias e no sistema político-jurídico do Estado Providência. ${ }^{23} \mathrm{Com}$ isso, o desequilíbrio entre as funções dos poderes de Estado (Executivo, Legislativo e Judiciário) altera a concepção do constitucionalismo estável, levando o Executivo a promover a edição de normas de comportamento e realizar políticas visando afastar a confusão estabelecida pela produção desordenada de textos legais. Na medida em que esse sistema normativo parece ter um potencial ilimitado, levando a um comportamento incessante de novas regras e de novas matérias de regulação, a tendência é o esvaziamento da própria função da lei. ${ }^{24}$

Jose Eduardo Faria menciona, ainda, a questão da inflação jurídica, pela produção acelerada de normas e a consequente "morte do direito":

Esse processo leva à própria anulação do sistema jurídico, pois, quando os direitos se multiplicam, multiplicam-se na mesma proporção as obrigações; e estas, ao multiplicarem os créditos, num círculo vicioso cuja continuidade culminaria na absurda situação de existirem apenas devedores, todos sem direito algum. Esse é o potencial corrosivo da inflação jurídica - o risco da própria morte do direito. ${ }^{25}$

Conclui-se que este processo de inflação jurídica gera ainda mais crise pelo agravamento de tensões entre as estruturas e pelo grau de não efetividade do poder de regulação, direção e intenção estatal, de modo que os efeitos da globalização econômica e da revolução tecnológica repercutem na ordem do Direito, com os seguintes destaques, na análise de Jose Eduardo Faria:

a. Mundialização na economia, mediante internacionalização dos mercados de consumo e repercussões na flexibilização das fronteiras;

b. Desconcentração dos organismos estatais pelas crescentes privatizações;

c. Desterritorialização e reorganização do espaço da produção e alteração nas relações de trabalho;

d. Fragmentação nas atividades produtivas nos diferentes territórios;

e. Expansão de um direito paralelo ao dos Estados, como decorrência da proliferação dos foros de negociações descentralizados estabelecidos pelos grandes grupos empresariais. ${ }^{2 \hat{6}}$

As consequências são inúmeras, mas o denominador comum, como se vê, é o esvaziamento da soberania e da autonomia dos Estados, sendo certo

\footnotetext{
${ }^{23}$ FARIA, José Eduardo. Direito e Globalização Econômica: Implicações e Perspectivas. São Paulo: Malheiros, 1996. p. 06.

${ }^{24}$ FARIA, José Eduardo. Direito e Globalização Econômica: Implicações e Perspectivas. São Paulo: Malheiros, 1996. p. 09.

${ }^{25}$ Idem.

${ }^{26}$ Idem.
} 
que muitos conglomerados de empresas têm PIB (Produto Interno Bruto) maior e com maior impacto econômico do que muitos países e nesse contexto, vê-se a internacionalização de muitos direitos nacionais e a expansão das normas privadas das organizações empresariais, resultado da autonomia frente a máquina estatal, deixando os Estados frequentemente enredados num pluralismo jurídico desordenado o que gera também uma crise de identidade e o deslocamento e a dispersão de poder.

\section{O MUNDO É PLANO: A EXPLOSÃO DAS NOÇÕES DE DISTÂNCIA, TEMPO E TRABALHO}

O processo de globalização da economia atual aliado ao uso crescente da tecnologia também trouxe implicações nas concepções de tempo, de espaço, de nação, de conhecimento, de cultura e de identidade, dentre outros conceitos e ainda dificuldades de uma nova experiência de tempo presente.

Stuart Hall em A Identidade Cultural na pós-modernidade, traça importante paralelo entre os movimentos de globalização do mercado e a compressão do espaço-tempo e identidade.

Que impacto tem a última fase da globalização sobre as identidades nacionais? Uma de suas principais características é a compressão no espaço-tempo, a aceleração dos processos globais, de forma que se sente que o mundo é menor e as distâncias mais curtas, que os eventos em um determinado lugar têm um impacto imediato sobre pessoas e lugares situados a uma grande distância. ${ }^{27}$

Menciona Stuart Hall que o impacto da globalização sobre a identidade é que o tempo e o espaço são também as coordenadas básicas de todos os sistemas de representação. Os meios de representação por ele elencados seriam as formas utilizadas pela cultura num determinado contexto histórico como a escrita, a pintura, o desenho, a fotografia ou na atualidade, os meios de comunicação (internet). Alterações na representação produzem consequentemente mudanças estruturais na compressão de tempo-espaço e na formação da identidade. ${ }^{28}$

Há ainda a concepção da separação entre espaço e lugar. Hall utilizando-se das concepções de Giddens menciona que o "lugar" é específico, concreto, conhecido, familiar, delimitado:

(...) nas sociedades pré-modernas, o espaço e o lugar eram amplamente coincidentes, uma vez que as dimensões espaciais da vida social eram, para a maioria da população, denominadas pela presença - por uma atividade localizada. A modernidade separa, cada vez mais, o espaço do lugar, ao reforçar relações entre os outros que estão "ausentes", distantes

\footnotetext{
${ }^{27}$ HALL, Stuart. A Identidade Cultural na Pós-modernidade. 11. ed., Rio de Janeiro: DP\&A Editora, 2011. p. 69.

${ }^{28}$ Idem.
} 
(em termos de local), de qualquer interação face a face. Nas condições da modernidade os locais são inteiramente penetrados e moldados por influências sociais bastante distantes deles. O que estrutura o local não é simplesmente aquilo que está presente na cena; a "forma visível" do local oculta as relações distanciadas que determinam sua natureza. ${ }^{29}$

Os espaços permanecem fixos e neles que temos raízes. Entretanto, o espaço pode ser "cruzado" num piscar de olhos - por avião a jato, por fax ou por satélite. ${ }^{30}$

Há, ainda, interações importantes na difusão do consumismo, pois quanto mais a vida social se torna mediada pelo mercado global de estilos, lugares e imagens, pelas viagens internacionais, pelas imagens da mídia e pelos sistemas de comunicação globalmente interligados, mais as identidades se tornam desvinculadas de tempos, lugares, histórias e tradições específicos e parecem "flutuar livremente". ${ }^{31}$

Muitos teóricos argumentam que o efeito geral desses processos globais tem sido enfraquecer ou solapar formas pessoais e nacionais de identidade cultural. Há, para estes teóricos, afrouxamento de fortes identificações com a cultura nacional e reforço de outros laços e lealdades culturais, "acima" e "abaixo" do nível do Estado-nação. ${ }^{32}$ Nos aspectos de direitos ou cidadania as identidades permanecem fortes, mas as identidades locais, regionais e comunitárias, vêm se tornando mais importantes. Colocadas acima do nível da cultura nacional, as identificações globais começam a deslocar e, algumas vezes, apagar as identidades nacionais. ${ }^{33}$ A questão do consumo também é considerada:

(...) os fluxos de capitais, entre as nações, o consumismo global criam possibilidades de "identidades partilhadas" - como "consumidores" para os mesmo bens, "clientes" para os mesmos serviços, "públicos" para as mesmas mensagens e imagens - entre pessoas que estão bastantes distantes umas das outras no espaço e no tempo. Na medida em que as culturas nacionais tornam-se mais expostas a influências externas, é difícil conservar as identidades culturais intactas ou impedir que elas se tornem enfraquecidas através do bombardeamento e da infiltração cultural. ${ }^{34}$

O poder do capital se amplia sem enfrentar diretamente as leis nacionais e sem o consentimento explícito de parlamentos ou governos graças às novas

\footnotetext{
${ }^{29}$ GIDDENS, Arthut apud. HALL, Stuart, idem, p. 73.

${ }^{30}$ HALL, Stuart. A Identidade Cultural na Pós-modernidade. 11. ed., Rio de Janeiro: DP\&A Editora, 2011. p. 73.

${ }^{31}$ Idem. p. 75.

${ }^{32}$ Idem.

${ }^{33}$ Idem.

${ }^{34}$ HALL, Stuart. A Identidade Cultural na Pós-modernidade. 11. ed., Rio de Janeiro: DP\&A Editora, 2011. p. 73 e 74.
} 
tecnologias de informação que oferecem a possibilidade de encolher os horizontes temporais e abolir as distâncias. O agente econômico global, por ser transacional, estende seu poder explorando as brechas de diferentes sistemas jurídicos nacionais. ${ }^{35}$

Gilberto Dupas em O poder dos atores e a nova lógica econômica global pontua o atual papel desenvolvido pelas corporações:

(...) os grandes grupos vão construindo seu próprio arcabouço legal, incluindo os padrões e as normas em relação ao trabalho, os contratos e os processos de arbitragem internacional. As antigas soberanias do Estado-nação passam agora a ser compartilhadas entre Estados e atores econômicos. O poder vai deixando de ser público e acaba, de fato, ocupando vazios criados pela lógica global e editando as novas normas de direito internacional. Assim, as empresas transacionais passam a tomar decisões quase políticas. Governos e opinião pública vão se transformando em espectadores das tomadas de decisão corporativas maximizantes do lucro, sem nenhuma legitimação democrática. ${ }^{36}$

Como se observa, as consequências do processo de globalização extrapolam as perspectivas do processo econômico e criam realidades políticas com repercussões, inclusive nas relações de trabalho:

(...) quem legitima as decisões das corporações sobre inovações e vetores tecnológicos, que definem condições de empregabilidade mundial - via automação e terceirização que podem suprimir empregos e baixar salários? Sobre essas ações de responsabilidade direta dos atores globais não há clara definição de responsabilidade nem sistema legal, político ou social que as aprove ou legitime. ${ }^{37}$

\section{DIVERSIDADE; ÉTICA E EDUCAÇÃO INTERCULTURAL PROFUNDA}

A crise da modernidade evoca a ideia de devir (mudanças, transformações). Essa crise do tempo reformula nova apreensão das relações de identidade cultural. Noutras palavras, as sociedades contemporâneas e multitemporais estabelecidas pela convivência pluriétnica e pluricultural, deslocam do lugar, estabelecido no discurso da modernidade, as narrativas homogeneizadoras, cuja diferença era pensada com a segurança do distanciamento. Num mundo marcado pelo fenômeno da imigração (pós-colonial), a educação intercultural se constitui como um dos maiores desafios. ${ }^{38}$

\footnotetext{
${ }^{35}$ DUPAS, Gilberto. O Poder dos Atores e a Nova Lógica Econômica Global. Ensaio preparado para Conferência Brasil e União Européia Ampliada. Rio de Janeiro, set. 2004. p. 17.

${ }^{36}$ Idem.

${ }^{37}$ Idem.

${ }^{38}$ LINHARES DA SILVA, Mozart. Educação Intercultural e Pós-modernidade. Revista Mal-estar e Subjetividade, vol. 3, $\mathrm{n}^{\circ} 1$, mar. 2003. p. 153.
} 
Surge o conceito de uma "pós-modernidade", porém a pós-modernidade não surge como algo pensado, não é fruto de uma corrente filosófica. Muito menos constitui um grupo unitário e homogêneo de valores ou modificações facilmente identificáveis, mas configura como um movimento que traz instabilidade e num contexto claro de "crise". Certa sensação de instabilidade, de incerteza, de indeterminismo paira no ar, simultaneamente a fluxos e ondas de determinismo, de estabilidade conservadora, de certezas e de verdades modernas.

As revoluções que se processam afetam, sobretudo, a dimensão cultural. Ora, esta afetação cultural, por óbvio, gera um choque de culturas entre o novo e o velho, que, até que se estabilizem as crenças e se estabeleçam consensos de homogeneidade, geram expectativas, que só podem ocorrer no plano cultural. Todo processo cultural é sempre um processo de reavaliação e de revaloração: a história das culturas é a tradução disto. No entanto, quando a intensificação das modificações reclama uma modificação simultânea, intensa e profunda de todas as dimensões pelas quais se propõe (transformações de hábitos de consumo, dos modelos de comportamento, das atitudes sexuais, dos sentidos da moda, da vertiginosa aceleração das relações de comunicação, das transformações institucionais), está-se mais do que diante de um processo de confronto de gerações com valores diferentes, uma vez que surge uma demanda por uma nova educação.

Sobre os desafios da crise da modernidade, Mozart Linhares da Silva em seu artigo Educação intercultural e pós-modernidade exemplifica:

(...) questões como identidade, tolerância, hibridismo, multiculturalismo, alteridade, complexidade e heterogeneidade, entre outras, figuram como temas constantes nos debates atuais acerca da crise da modernidade e do fenômeno da globalização. Na realidade, estes termos colocam em xeque alguns aspectos profundamente arraigados a desestruturação da modernidade como uma forma de civilização calcada no saber laico, numa concepção de tempo progressivo e linear, racionalista e antropocêntrica e, sobretudo, homogeneizadora. ${ }^{39}$

O contexto fragmentário das identidades é resultado das novas concepções de tempo e distância. Aspectos culturais também irão provocar estranhamentos dado às urgências das novas realidades ocorridas. Mozart Linhares da Silva traz ainda a menção de que "o mundo globalizado não se caracteriza apenas pela circulação frenética de objetos, mas também pela frenética migração", que irá provocar novo fenômeno:

(...) este fenômeno de frenética migração desafia os modelos educacionais cuja origem remonta a um tempo pedagógico estratégico para os

39 LINHARES DA SILVA, Mozart. Educação Intercultural e Pós-modernidade. Revista Mal-estar e Subjetividade, vol. 3, $n^{\circ}$ 1, mar. 2003. p. 153. 
Estados-nação. Desde a Revolução Francesa, a educação passou ser estratégica para os Estados Modernos. Por vários motivos, entre eles, pelo cumprimento de um papel moralizador e identitário. Era a partir da escola que a narrativa da nação formava a tecitura sobre a qual as diferenças nacionais eram exaltadas e enaltecidas as qualidades próprias da nação, em particular. ${ }^{40}$

A educação que tinha um papel estratégico e disciplinar, pois formatava conceito de espaço-tempo formador de identidade no mundo atual, não comporta a fragmentação discursiva, que necessita de um novo objeto pedagógico que contorne a ideia de povo unificado. O desafio da educação intercultural é corresponder às idiossincrasias do local e do universalismo global, a um só tempo. ${ }^{41}$

Há, ainda, a questão que diz respeito aos efeitos das novas tecnologias no entendimento da memória e das identidades que navegam no mundo contemporâneo, uma vez que ela será útil para pensar a educação, nesse processo de complexificação do mundo globalizado, cuja interculturalidade é um dos aspectos relevantes. ${ }^{42}$

Edgar Morin em Os Sete Saberes necessários à educação do futuro menciona a importância do ensino:

O ensino deve buscar a compreensão mútua entre os seres humanos, quer dos próximos, quer dos estranhos, disso de fato decorre a necessidade de estudar a incompreensão a partir de suas raízes, suas modalidades e seus efeitos. Este estudo é tanto necessário porque enfocaria não os sintomas, mas as causas do racismo, da xenofobia, do desprezo. $^{43}$

Os saberes concebidos por Morin em conjunto promoveriam uma "antropo-ética", segundo o qual a sociedade deveria ser pensada a partir de uma cidadania terrena, como habitantes de um mesmo espaço.

Vê-se nesta perspectiva um panorama para um novo trato da informação e do conhecimento e nesse sentido a educação intercultural profunda depende da construção de outra narrativa, distanciada das estratégias identitárias da nação moderna e atenta à igualdade na diversidade ${ }^{44} \mathrm{com}$ vias a uma efetiva partilha do conhecimento.

\footnotetext{
${ }^{40}$ LINHARES DA SILVA, Mozart. Educação Intercultural e Pós-modernidade. Revista Mal-estar e Subjetividade, vol. 3, $\mathrm{n}^{\circ}$ 1, mar. 2003. p. 153.

41 Idem.

${ }^{42}$ Idem.

${ }^{43}$ MORIN, Edgar. Os Sete Saberes Necessários à Educação do Futuro. São Paulo: Contez, 2001. p. 55.

${ }^{44}$ LINHARES DA SILVA, Mozart. Educação Intercultural e Pós-modernidade. Revista Mal-estar e Subjetividade, vol. 3, $\mathrm{n}^{\circ} 1$, mar. 2003. p. 158.
} 


\section{A PARTILHA DO CONHECIMENTO}

Diante da desigualdade crescente encontrada nas sociedades contemporâneas, fruto de um processo econômico global que provocou alterações nas identidades nacionais e locais e mesmo pessoais, e num contexto revolução tecnológica, responsável por modificações nas noções clássicas de distância, tempo e espaço, e ao final uma demanda por um novo modelo educacional, há de se indagar se há um movimento de projeção destas sociedades pluralistas para formação de uma sociedade do conhecimento e qual a perspectiva para a partilha do conhecimento.

Boaventura de Sousa Santos aborda a questão das desigualdades raciais para o dimensionamento de problemas encontrados na chamada sociedade da informação, que é desigual, e quais as dificuldades de um movimento para a projeção uma sociedade do conhecimento pluralista e compartilhada. ${ }^{45}$

O sociólogo aborda a vocação para desigualdade social que as sociedades capitalistas trazem no seu desenvolvimento e menciona que na Europa as políticas de igualdade de oportunidade, assentadas nos sistemas nacionais de educação, saúde e previdência social, historicamente foram mais seriamente tratadas do que nos Estados Unidos. O mercado adquire funções muito mais de regulação social do que o próprio Estado, e as políticas de oportunidade dão lugar às políticas de emprego e empregabilidade. ${ }^{46}$

As políticas dos Estados, para Boaventura de Sousa Santos, deveriam visar uma integração pluralista através das seguintes ações:

Políticas ativas de emprego e de educação articuladas com discriminação positiva ou ação afirmativa; educação intercultural profunda; promoção de diversidade identitária e cultural no espaço público como veículo de intermediação com os sistemas políticos nacionais - parlamentos que reflitam a diversidade cultural e étnica - e local, por meio da participação em conselhos sociais municipais e instâncias de democracia participativa; políticas sociais universalistas (renda básica, habitação social, etc.) que evitem a concentração de minorias (por vezes) em guetos; política de fortalecimento da diversidade. ${ }^{47}$

Os autores referidos neste artigo abordam de forma frequente o caráter desigual e injusto da sociedade da informação assegurado pelo o abismo existente entre os chamados países desenvolvidos e os subdesenvolvidos, ou entre os hemisférios norte e sul, os crescentes problemas derivados das imigrações e conflitos étnicos que assumem proporções mais intensas e diversificadas, a crise dos mercados de trabalho e na valorização da mão de

\footnotetext{
${ }^{45}$ SOUZA SANTOS, Boaventura de apud BARBOSA, Marco Antonio. Poder na Sociedade da Informação. In PAESANI, Liliana Minardi. (Coordenadora) O Direito na Sociedade da Informação. São Paulo: Atlas, 2007. p. 59.

${ }^{46}$ Idem.

${ }^{47}$ Idem.
} 
obra, a ausência da promoção ao respeito às diversidades culturais e a proteção ao conhecimento das sociedades tradicionais e acima de tudo indicam que há de se atentar para o papel que o mercado exerce sobre a informação e o conhecimento, que agora mais do que nunca, adquirem o valor de produto:

A cidadania é revogada a favor do consumidor, que cede sua força de trabalho para consumir aquilo que o mercado lhe impõe que deve ou precisa consumir. $\mathrm{O}$ mercado age com as ferramentas informacionais e de comunicação tecnologicamente desenvolvidas para conformar até mesmo as próprias identidades aos seus interesses. ${ }^{48}$

Sloterdijk chamando este tempo presente de tempo da não responsabilização pessoal diz que o efeito dessa não responsabilidade decisiva no campo do conhecimento incide sobre o que se poderia chamar de os custos do deslocamento da cultura.

Se aquilo que se denomina de homem completo devia no passado movimentar-se para encontrar acesso às fontes de cultura dispersas, esotéricas e custosas, basta agora, cada vez mais, aprender o manejo das técnicas performáticas de acesso para ir procurar os conteúdos desejados no endereço preciso onde se encontra o próprio si mesmo. A possibilidade de ir procurar facilmente as coisas se desenvolve para se tornar em um procedimento anti-extroversão universalmente disponível graças ao qual o princípio de experiência é anulado. Se o sujeito empírico histórico é necessariamente um pesquisador, e mesmo um centro vivo de coleção da experiência, as máquinas de pesquisas atuais e as novas técnicas de estocagem lhe endereçam um sinal segundo o qual ele pode se livrar de suas cargas clássicas. O gesto atual que exprime da maneira a mais perfeita a passagem à era que segue aquela da experiência é a téletransferência [transferência eletrônica de dados]. Ela encarna a liberação da exigência de fazer experiências. Com ela produz-se um regime de conhecimento pós-pessoal, pós-literário, pós-acadêmico. ${ }^{49}$

\section{CONSIDERAÇÕES FINAIS}

Conclui-se que a informação e o conhecimento na atualidade foram transformados em mais um dos produtos para o mercado, ou melhor, no principal produto e que o mercado age com as ferramentas informacionais e de comunicação tecnologicamente desenvolvidas para conformar até mesmo as próprias identidades aos seus interesses, sendo as mídias de massa o principal veículo.

\footnotetext{
${ }^{48}$ SOUZA SANTOS, Boaventura de apud BARBOSA, Marco Antonio. Poder na Sociedade da Informação. In PAESANI, Liliana Minardi. (Coordenadora) O Direito na Sociedade da Informação. São Paulo: Atlas, 2007. p. 59.

${ }^{49}$ SLOTERDIJK, Peter. Le Palais de Cristal. Traduit de l'allemand par Olivier Mannoni. France: Pluriel, 2010. Tradução pessoal, p. 315.
} 
Constata-se o caráter desigual e injusto da sociedade da informação assegurado pelo abismo existente entre os chamados países desenvolvidos e em desenvolvimento, entre os hemisférios norte e sul, os crescentes problemas derivados das imigrações e conflitos étnicos que assumem proporções mais intensas e diversificadas, a crise dos mercados de trabalho e na valorização da mão de obra, a ausência da promoção ao respeito às diversidades culturais e a proteção ao conhecimento das sociedades tradicionais.

A formação de uma vindoura "sociedade do conhecimento" que caminhe para a partilha do conhecimento se transforma em algo utópico. Valores, como ética e moral, adquirem maior importância, uma vez que o próprio Direito encontra-se esvaziado frente ao deslocamento do poder que agora não é mais do Estado e sim fragmentado e sob o crescente domínio de múltiplos conglomerados econômicos.

A sociedade da informação no trato do conhecimento realiza muito menos do que se propõe e transmite informação ambivalente, manipulada e manipulável, assim como, a globalização engloba muito menos pessoas e povos do que seu discurso ideológico de legitimação pretende.

O aspecto educacional parece despontar como o caminho mais ético no trato da informação e sua tentativa de agregar conhecimento e partilha-lo. Trata-se de algo com certa dose de utopia, mas a própria educação não pode ser pensada na perspectiva do presente, mas na de futuro, principalmente quanto aos valores.

Há uma crise ética que tem como principal dificuldade a tensão entre informação que visa ao conhecimento e a informação fruto do objeto de consumo e resultado da crise da pós-modernidade com repercussões nas nossas noções clássicas de tempo, espaço, cultura e identidade cultural.

\section{REFERÊNCIAS BIBLIOGRÁFICAS}

ARANTES, Otilia; VAINER, Carlos; MARICATO, Emilia. A Cidade do Pensamento Único: desmanchando consensos. Petrópolis: Vozes, 2000.

ASCENSÃO, José de Oliveira. Estudos sobre Direito da Internet e da Sociedade da Informação. Coimbra: Almedina, 2001.

BARBOSA, Marco Antonio. Poder na Sociedade da Informação. In PAESANI, Liliana Minardi. (Coordenadora) O Direito na Sociedade da Informação. São Paulo: Atlas, 2007. BUCKINGHAM, Will e colaboradores. O Livro da Filosofia. São Paulo: Globo, 2011.

DEMO, Pedro. Ambivalências da Sociedade da Informação. Ciência da Informação, Brasília, v. 29, nº 2, p. 37-42, maio/ago. 2000.

DUPAS, Gilberto. O Poder dos Atores e a Nova Lógica Econômica Global. Ensaio preparado para Conferência Brasil e União Européia Ampliada. Rio de Janeiro, set. 2004. FARIA, José Eduardo. Direito e Globalização Econômica: Implicações e Perspectivas. São Paulo: Malheiros, 1996.

HALL, Stuart. A Identidade Cultural na Pós-modernidade. 11. ed., Rio de Janeiro: DP\&A Editora, 2011. 
LINHARES DA SILVA, Mozart. Educação Intercultural e Pós-modernidade. Revista Mal-estar e Subjetividade, vol. 3, nº 1, mar. 2003.

LYOTARD, Jean-François. A Condição Pós-moderna. Rio de Janeiro: José Olimpio Editora, 1988.

MACHADO, Roberto. Ciência e Saber: a trajetória da arqueologia de Michel Foucault. Rio de Janeiro: Graal, 1981.

MORIN, Edgar. Os Sete Saberes Necessários à Educação do Futuro. São Paulo: Contez, 2001.

SLOTERDIJK, Peter. Le Palais de Cristal. À l'intérieur du capitalisme planetaire. France: Pluriel, 2010. 